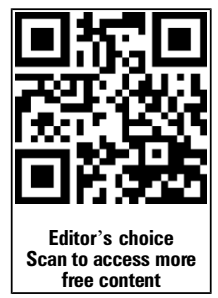

free content

\title{
Fifteen-minute consultation: when is a seizure not a seizure? Part 2, the older child
}

\author{
Mohamed OE Babiker, ${ }^{1}$ Manish Prasad ${ }^{2}$
}

\begin{abstract}
${ }^{1}$ Department of Paediatric Neurology, Bristol Royal Hospital for Children, Bristol, UK ${ }^{2}$ Department of Paediatric Neurology, Leicester Royal Infirmary, Leicester, UK
\end{abstract}

\section{Correspondence to}

Dr Manish Prasad, Department of Paediatric Neurology, Leicester Royal Infirmary, Leicester LE1 5WW, UK; m.prasad@nhs.net

Received 4 February 2015 Revised 11 June 2015 Accepted 12 June 2015 Published Online First 1 July 2015

\section{CrossMark}

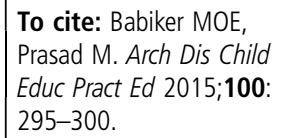

\begin{abstract}
Paroxysmal non-epileptic events (PNEs) refer to episodic changes in behaviour, sensation or consciousness that lead to unusual movements, which may resemble epileptic seizures, but are not, due to excessive neuronal firing in the cerebral cortex. A significant proportion of patients seen in epilepsy clinics do not actually have epilepsy. Therefore, it is paramount for clinicians to be able to recognise these transient non-epileptic events in order to avoid unnecessary antiepileptic treatments and to provide appropriate management as required. These PNEs can be observed within the context of a neurological disorder such as migraine or with no direct neurological basis such as simple tics. In this review, we have described common PNEs presenting in school-age children and adolescents alongside the clinical approach to differentiate them from epileptic seizures. PNEs occurring in infancy and younger children have been covered in our first review of this series.
\end{abstract}

\section{INTRODUCTION}

Paroxysmal neurological or nonneurological events in children and adolescents that mimic epileptic seizures (ES) are common. These range from migraine to simple tics. Epilepsy, by virtue of its episodic nature, is by far the most important consideration in the diagnostic paradigm.

One of the reasons why epilepsy misdiagnosis is common is the potential difficulty in recognising these non-epileptic events. Over reliance on investigations such as the standard electroencephalogram (EEG) is also contributory. Non-specific EEG abnormalities can be seen in normal children, and a normal interictal EEG does not exclude epilepsy on the other hand. ${ }^{1}$ In fact, the commonly asked question 'is it epilepsy?' can rarely be answered by a $20 \mathrm{~min}$ EEG recording, making this an inappropriate request on most occasions. ${ }^{2}$ Thus, the most helpful approach is of an informative history from an eyewitness combined with a video account when possible with the occasional use of a prolonged EEG video telemetry in difficult cases.

In the first instance, health professionals should have a working knowledge of the semiological features of ES to confidently diagnose paroxysmal nonepileptic events (PNEs). Along with clinical experience, accesses to educational websites that contain teaching videos serve such a purpose. An example is the International League Against Epilepsy sponsored free website (https://www. epilepsydiagnosis.org). It is not uncommon these days for parents to 'Google' and look up online videos (eg, on YouTube) that might (or might not) be relevant to their child's episodes even before coming to the clinic appointment, and clinicians should be mindful of this.

In this article, we present the commonly referred PNEs that may imitate ES in school-age children and adolescents. A diagnostic approach is also discussed, focusing on how these conditions are identified. Detailed pathophysiology and management are beyond the scope of this paper.

\section{SYNCOPE}

Syncope can be defined as a transient loss of consciousness due to a 'sudden decrease in cerebral perfusion with oxygenated blood, either from a reduction in cerebral blood flow itself or from a drop in its oxygen content, or a combination of these'. ${ }^{3}$ This is more common in adolescents than any other age group, and up to $15 \%$ of children will experience at least one episode before 18 years of age. ${ }^{4}$ 
Precipitants may include sudden change in posture, acute emotional upset, hair grooming and micturition. Presyncopal symptoms include dizziness, nausea, feeling hot, sudden 'greying out', a rushing noise in the ears and vague abdominal discomfort. These symptoms are followed by a sensation of confusion and loss of consciousness. ${ }^{5}$ Up-rolling of the eyes, urinary incontinence and shaking of limbs can all occur during syncope, potentially causing diagnostic confusion with ES. Syncopal attacks associated with tonic, clonic, tonic-clonic and hypermotor movements are called convulsive syncope. ${ }^{5}$ Recovery may be quick, within seconds in 'mild' syncope, or there may be prolonged postictal confusion or sleeping 'severe' syncope. ${ }^{5}$

There is no one single clinical feature that reliably differentiates between a convulsive syncopal attack and an ES. Tongue biting was found to have a specificity of $96 \%$ and a sensitivity of $33 \%$ for ES in one systemic review. ${ }^{6}$ Biting at the tip of the tongue was more indicative of convulsive syncope, whereas biting at the tongue sides was seen in ES as demonstrated in one paediatric study. ${ }^{7}$ Urinary incontinence has no value in differentiating ES from other paroxysmal events, including syncope. ${ }^{8}$

Blood pressure should always be recorded in addition to a 12-lead ECG. A cardiac cause is suspected if syncope is exercise related or sleep related, or if there is a family history of sudden death, abnormal cardiovascular examination or abnormal ECG. In these cases, referral to cardiology is recommended. ${ }^{5}$ Other investigations, including head-up tilt test, are occasionally required if doubt about diagnosis persists, or if the attacks are very severe or frequent.

\section{TICS}

Tics are the most common involuntary paroxysmal movements observed in children with a nearly $20 \%$ prevalence among school-age children, according to one survey. ${ }^{9}$ Typical age of onset is between 4 and 8 years. Tics can be motor or vocal. Common motor tics include eye blinking, head and neck craning, facial grimace, arm twitching and shoulder shrugging. Common vocal tics include throat clearing, squeaking noises, sniffling and coughing. Characteristically, tics are preceded by a premonitory urge, sometimes called a 'tic alert', with a relative sense of relief following the tic. Tics tend to disappear during sleep, are exaggerated by anxiety or stress. Their severity and frequency follow a waxing and waning course, with most children eventually growing out of their tics. It is not uncommon for children to present with an explosive onset of tics, which can, understandably, be a source of anxiety for parents and clinicians alike.

Comorbid conditions may include attention deficit hyperactivity disorder, obsessive-compulsive behaviours and learning disability. ${ }^{9}$ Differentiation from ES is by obtaining a history of the 'tic alert', and the partial ability to suppress the tic in addition to the stereotyped behaviours explained above.

\section{NON-EPILEPTIC ATTACKS}

Non-epileptic attacks (NEAs) are episodes of variable motor, sensory and cognitive symptoms secondary to impairment of self-control, and not caused by abnormal cortical neuronal discharges. There is no universal agreement on the best terminology, and many have been used such as non-ES, pseudo seizures, psychogenic non-ES, functional/hysterical seizures, dissociative seizures and conversion seizures. However, care must be exercised as some of these terms are confusing and even pejorative.

In a recent British Paediatric Surveillance Unit study that looked at the incidence of non-transient conversion disorders in children aged 7-15 years in the UK and Ireland, 'non-ES' were diagnosed in $40 \%$ of those diagnosed. ${ }^{10}$ A prospective study found that $13 \%$ of the children with PNEs referred to a secondary care clinic had 'psychogenic seizures' with a median age of 12 years. ${ }^{11}$ NEAs are common in children and young people with epilepsy, which can cause a diagnostic dilemma in some cases.

A diagnosis of NEAs is serious. Several studies have shown that quality of life is significantly lower in

Box 1 Helpful diagnostic features (usually in combination) in non-epileptic attacks

Duration of 'convulsive seizure' $>5-10$ min

- Fluctuation in motor activity

Side-to-side head and/or body movements

Tremor-like movements of limbs

Thrashing movements

Self-protective manoeuvres (although self-injury can occur)

- Eye closure during the attack and resistance to passive eye movements

- Complex vocalisation with emotional content either during or after the attack

- Sudden falls with prolonged periods of lying

- Motionlessness

D Distractibility

- Opisthotonus

- Physical examination during or after the attack (if witnessed): ${ }^{18}$

Preserved corneal reflex (commonly lost after a generalised tonic seizure)

Responsive pupils

Resistance to opening the eyes if they are closed Preserved protective mechanisms (eg, can be tested by holding the hand over the face then dropping it)

Response to verbal requests 
Box 2 Unhelpful features in differentiating

non-epileptic attacks from epileptic seizures (ES)

- Reported aura

Stereotyped (or non-stereotyped) movements

Urine (or faecal) incontinence

- Report of tongue biting (except for marks of biting on the side of the tongue in ES)

Pelvic thrusting

- Self-injury

- Postictal confusion

- Autonomic dysfunction such as tachycardia and pupil dilatation

- Male gender or younger age

- A normal standard electroencephalogram

- Postictal serum prolactin or plasma creatine kinase levels

- A prior diagnosis of epilepsy

- Response to antiepileptic drugs (possibility of a placebo effect)

patients with NEAs in comparison with those with epilepsy. ${ }^{12-14}$ Anxiety, mood disorders, emotional problems and depression are over-represented in this group of children. More alarmingly, an adult study showed that $27 \%$ of patients with 'psychogenic non-ES' had episodes that mimicked status epilepticus, and were admitted to an intensive care unit. ${ }^{15}$

There is no single clinical feature that differentiates between NEAs and ES. Broadly speaking, ES are usually unprovoked, have an abrupt onset, brief and highly stereotyped. Boxes 1 and 2 outline some of the features that, collectively, have a higher sensitivity for NEAs, as well as the features that are not helpful in differentiating between both entities.

A few studies have demonstrated that apparent lack of responsiveness with subtle motor phenomena is more common in younger patients, whereas convulsive movements are seen in older children. ${ }^{16}$

The following are practical points to consider:

- A request can be made in the appointment letter asking the parents to bring video footage of the events in question.

- Allow time to see the child/young person separately.

- Are there any triggers or contexts in which the events are likely to happen within (ie, stressful situations)?

- A detailed description of the attacks. Patients commonly do not give detailed description of the attack itself and instead focus on the details surrounding it. ${ }^{17}$

- Explore what the patient/parents think is wrong with them.

Table 1 Migraine variants that can potentially be misdiagnosed as epilepsy (diagnostic criteria for each condition are described in the International Headache Society Classification (ICHD-II) website: http://ihs-classification.org/en/)

\begin{tabular}{|c|c|}
\hline Migraine syndrome & Comments \\
\hline Migraine with aura & $\begin{array}{l}\text { An aura is a transient subjective feeling of unusual visual symptoms, abnormal sensations (numbness } \\
\text { or 'pins and needles') or speech disturbance that typically precedes onset of headache } \\
\text { - Aura symptoms are described in up to one-third of childhood migraine } \\
\text { - Onset is gradual over } 5-20 \text { min (as opposed to seizures) and lasts }<60 \text { min } \\
\text { - Abrupt onset of visual aura may indicate occipital lobe epilepsy }\end{array}$ \\
\hline $\begin{array}{l}\text { Typical aura without headache } \\
\text { (acephalgic migraine) }\end{array}$ & - Typical aura with non-migraine headache is also described \\
\hline Hemiplegic migraine & $\begin{array}{l}\text { Either familial or sporadic } \\
\text { Typical presentation is with stroke-like hemiparesis with a migrainous-type headache } \\
\text { - Clinically evident weakness must be demonstrated } \\
\text { - May be confused with Todd's (postictal) paresis }\end{array}$ \\
\hline Acute confusional migraine & $\begin{array}{l}\text { Attack is marked with abrupt onset of agitation, disorientation and behavioural changes } \\
\text { Confusion lasts from minutes to hours } \\
\text { There may be no recollection of the event and the associated headache } \\
\text { A diagnosis of exclusion }\end{array}$ \\
\hline 'Alice in Wonderland' syndrome & $\begin{array}{l}\text { A form of migraine with atypical visual aura } \\
\text { Abnormal visual illusions with spatial distortions } \\
\text { - The differential diagnosis includes occipital lobe epilepsies }\end{array}$ \\
\hline Retinal migraine & - Episodic reversible monocular visual disturbance associated with ipsilateral retro-orbital pain \\
\hline Basilar-type migraine & $\begin{array}{l}\text { Symptoms (and signs) of brainstem or posterior fossa involvement } \\
\text { - Attacks of dizziness, vertigo, ataxia, dysarthria and diplopia for minutes or up to an hour followed } \\
\text { by the hadache phase } \\
\text { May be associated with decreased level of consciousness } \\
\text { The combination of the above features may be confused with complex focal seizures }\end{array}$ \\
\hline
\end{tabular}




\section{Box 3 Differentiating points between migraine and epilepsy}

- Epileptic seizures are usually brief and commonly marked by positive motor (eg, twitching) and sensory symptoms. In contrast, negative symptoms (eg, weakness, numbness) are typically experienced during the aura phase in migraine, and loss of consciousness is uncommon.

- Aura duration is shorter in epilepsy (usually seconds to a minute or two), whereas in migraine, it lasts longer than $5 \mathrm{~min}$ and typically less than $60 \mathrm{~min}$, and the onset is subtle.

- Migrainous visual aura is usually monocoloured (ie, black and white) with linear or zigzag patterns and associated scotomas. On the other hand, epileptic aura is more complex, and when visual phenomena occur, they are often multicoloured and circular or spherical.

- Other types of epileptic auras (eg, feelings of déjà vu) are rare in migraine.

- Asking the children to draw their visual auras can be diagnostically valuable, and helps differentiate between both disorders.

- Children with migraine may have electroencephalogram (EEG) abnormalities, including excessive photic responses, focal slowing and even epileptiform discharges. ${ }^{20}$ However, none of these changes are specific, and EEG should not be employed to diagnose migraine.

- A history of previous functional symptoms might support the diagnosis. However, be sensitive to previous 'negative' experiences from encounters with other health professionals who might have implied to them that 'it's all in their head!'
- A prior diagnosis of 'epilepsy' does not mean that the events in question are necessarily 'epileptic'. Between 10\% and $30 \%$ of adults with epilepsy have associated NEAs. ${ }^{18}$

- Questions about potential adverse social circumstances (such as bullying and maltreatment), stress and anxiety

Table 2 Examples of non-epileptic events encountered in children with neurodisability

\begin{tabular}{|c|c|}
\hline Condition & Examples of associated paroxysmal non-epileptic events \\
\hline Autistic spectrum disorder & $\begin{array}{l}\text { Motor stereotypies } \\
\text { - Self-stimulatory behaviours (eg, compulsive Valsalva manoeuvre leading to reflex anoxic seizures) } \\
\text { - Sensory processing issues (eg, unusual visual experiences) }\end{array}$ \\
\hline Cerebral palsy (all types) & $\begin{array}{l}\text { Associated dystonia (repetitive twisting movements) } \\
\text { Status dystonicus } \\
\text { Dyskinetic movement disorders (eg, choreoathetoid movements) } \\
\text { agitation episodes manifested by hypermotor or tonic spasm features (with or without autonomic } \\
\text { gastro-oesophageal reflux, constipation, orthopaedic problems, dental pain .... etc. Every effort should be made } \\
\text { to assess for pain and to rule these causes out }\end{array}$ \\
\hline Post brain injury & $\begin{array}{l}\text { Subcortical myoclonus } \\
\text { Tonic spasms } \\
\text { Paroxysmal autonomic instability with dystonia: tachycardia, hyperthermia, hypertension, agitation and extensor } \\
\text { posturing }\end{array}$ \\
\hline Intellectual disability & $\begin{array}{l}\text { Timeout phenomenon, in which, the child would appear to be staring blankly and become motionless. This is } \\
\text { usually situational. It may be mistaken for absence seizures } \\
\text { - Self-stimulatory behaviours (eg, rocking, spinning ... etc) }\end{array}$ \\
\hline Rett syndrome & $\begin{array}{l}\text { Hand stereotypies } \\
\text { Syncopal attacks secondary to hyperventilation, breath holding and prolonged QT interval } \\
\text { Abnormal behaviours (eg, 'screaming fits') }\end{array}$ \\
\hline Neiman-Pick type C & - Drop attacks secondary to cataplexy (sudden loss of muscle tone in response to intense emotions like laughter) \\
\hline $\begin{array}{l}\text { Drug-related movement } \\
\text { disorders }\end{array}$ & $\begin{array}{l}\text { Tics and motor stereotypies: can complicate the treatment course with methylphenidate } \\
\text { Oculogyric crisis: presents with dystonic ocular movements such as upward deviation of the eyes, periorbital } \\
\text { twitching and prolonged staring. Agents may include domperidone, metoclopramide and carbamazepine } \\
\text { Tardive dyskinesia: characterised by rhythmic movements of the tongue, face, trunk and extremities. Can } \\
\text { complicate prolonged treatment (>3 months) with a dopamine antagonist such as risperidone } \\
\text { - Status dystonicus secondary to sudden withdrawal of baclofen or benzodiazepines }\end{array}$ \\
\hline
\end{tabular}


Table 3 Some paediatric psychological disorders that may mimic seizures

\begin{tabular}{l} 
Disorder \\
\hline Panic attacks (PA)
\end{tabular}

are better left to the end after a good rapport has been built with the patient and parents.

- Seek information widely from school and other professionals involved.

The history alone or in combination with a video recording is usually sufficient to secure the diagnosis. A standard interictal EEG is not helpful, and should not be requested as it has the potential to contribute to diagnostic errors. ${ }^{18}$ Where uncertainty remains, video telemetry monitoring in a specialist centre is considered the 'gold standard'. 16

\section{MIGRAINE}

Individually, migraine and epilepsy are the most common paediatric neurological disorders seen in practice. Some migraine variants can present with episodic neurological symptoms such as disturbance of consciousness that can be confused with seizures. There is an increased frequency of migraine in children, with certain epilepsy syndromes such as benign rolandic epilepsy and Panayiotopoulos syndrome. Headache, which is usually the predominant symptom in migraine, is also frequently experienced in association with seizures. In a recent prospective paediatric study, both preictal and postictal headaches were reported in one-third of patients with epilepsy, more commonly reported in association with focal seizures. ${ }^{19}$ Migraine was prevalent in one-fifth of the patients in that study. ${ }^{19}$ Some of the migraine variants in children, which can cause diagnostic confusion, are presented in table 1 .

Despite their similarities, migraine and epilepsy are distinct disorders with important differences. A thorough careful history is paramount. Box 3 highlights important points, which can be helpful.

\section{SEIZURE MIMICS IN CHILDREN WITH NEURODISABILITY AND PSYCHOLOGICAL DISORDERS}

Although epilepsy is common in this heterogeneous group of children with neurodevelopmental disorders, seizure mimics are also common, and can be a source of diagnostic confusion. Table 2 provides examples of non-epileptic episodes associated with neurodisability. Equally, children with psychological disorders may present with episodic features that mimic seizures. These are described in table 3.

\section{CONCLUSION}

PNEs are a common source of misdiagnosis of epilepsy in older children and adolescents. A thorough knowledge of the various seizure mimics at all age groups is vital in avoiding the wrong diagnosis, inappropriate investigations and management.

Contributors Both MOEB and MP contributed equally and agreed with the final draft.

Competing interests None declared.

Provenance and peer review Commissioned; externally peer reviewed.

\section{REFERENCES}

1 The epilepsies: the diagnosis and management of the epilepsies in adults and children in primary and secondary care. Issued: January 2012 last modified: December 2013. NICE CG137. https://www.nice.org.uk/guidance/cg137/resources/guidancethe-epilepsies-the-diagnosis-and-management-of-the-epilepsiesin-adults-and-children-in-primary-and-secondary-care-pdf

2 Fowle AJ, Binnie CD. Uses and abuses of the EEG in epilepsy. Epilepsia 2000;41(Suppl 3):S10-18.

3 Stephenson J, McLeod K. Reflex anoxic seizures. In: David TJ, ed. Recent advances in paediatrics. Edinburgh: Churchill Livingstone, 2000:1-19. 
4 Lewis DA, Dhala A. Syncope in the pediatric patient. The cardiologist's perspective. Pediatr Clin North Am 1999;46:205-19.

5 Martin K, Bates G, Whitehouse WP. Transient loss of consciousness and syncope in children and young people: what you need to know. Arch Dis Child Educ Pract Ed 2010;95:66-72.

6 Brigo F, Nardone R, Bongiovanni LG. Value of tongue biting in the differential diagnosis between epileptic seizures and syncope. Seizure 2012;21:568-72.

7 Akor F, Liu NM, Besag FM, et al. Value of tongue biting in differentiating between epileptic seizures and syncope. Seizure 2013;22:328.

8 Brigo F, Nardone R, Ausserer H, et al. The diagnostic value of urinary incontinence in the differential diagnosis of seizures. Seizure 2013;22:85-90.

9 Jancovic J. Tourette's syndrome. N Engl J Med 2001;345:1184-92.

10 Ani C, Reading R, Lynn R, et al. Incidence and 12-month outcome of non-transient childhood conversion disorder in the UK and Ireland. Br J Psychiatry 2013;202:413-18.

11 Hindley D, Ali A, Robson C. Diagnoses made in a secondary care "fits, faints, and funny turns" clinic. Arch Dis Child 2006;91:214-18.
12 Szaflarski JP, Hughes C, Szaflarski M, et al. Quality of life in psychogenic nonepileptic seizures. Epilepsia 2003;44:236-42.

13 Karakis I, Montouris GD, Piperidou C, et al. Patient and caregiver quality of life in psychogenic non-epileptic seizures compared to epileptic seizures. Seizure 2014;23:47-54.

14 Testa SM, Schefft BK, Szaflarski JP, et al. Mood, personality, and health-related quality of life in epileptic and psychogenic seizure disorders. Epilepsia 2007;48:973-82.

15 Reuber M, Pukrop R, Mitchell AJ, et al. Clinical significance of recurrent psychogenic nonepileptic seizure status. J Neurol 2003;250:1355-62.

16 Reilly C, Menlove L, Fenton V, et al. Psychogenic nonepileptic seizures in children: a review. Epilepsia 2013;54:1715-24.

17 Stone J. The bare essentials: functional symptoms in neurology. Pract Neurol 2009;9:179-89.

18 Mellers JDC. The approach to patients with "non-epileptic seizures”. Postgrad Med J 2005;81:498-504.

19 Kanemura H, Sano F, Ishii S, et al. Characteristics of headache in children with epilepsy. Seizure 2013;22:647-50.

20 Oakley CB, Kossoff EH. Migraine and epilepsy in the pediatric population. Curr Pain Headache Rep 2014;18:402. 